\title{
ADULT ONSET HENOCH: SCHONLEIN PURPURA - AN UNUSUAL PRESENTATION
}

\section{SRUJITH CHANDRAKANTHI, OSHIN MANTRO, JAGADEESAN MOHANAN*, MERVIN KAYIPARAMBIL SOMAN, PRASANNA KARTHIK SUTHAKARAN, KANNAN RAJENDRAN}

Department of General Medicine, Saveetha Medical College Hospital, Saveetha University, Chennai, Tamil Nadu, India.

Email: drjagadeesan@gmail.com

Received: 15 May 2017, Revised and Accepted: 17 June 2017

\section{ABSTRACT}

Henoch-Schonlein purpura (HSP) is a common leukocytoclastic vasculitis seen in children. However, it is uncommon in adults. HSP is characterized by the classic tetrad of non-thrombocytopenic palpable purpura, arthritis or arthralgias, gastrointestinal, and renal involvement. We report a rare case of adult onset HSP with multi-organ involvement. Early recognition of multi-organ involvement is very important, especially in adults.

Keywords: Henoch schonlein purpura, Leucocytoclastic vasculitis, Palpable purpura, Adult HSP.

(C) 2017 The Authors. Published by Innovare Academic Sciences Pvt Ltd. This is an open access article under the CC BY license (http://creativecommons. org/licenses/by/4. 0/) DOI: http://dx.doi.org/10.22159/ajpcr.2017.v10i10.20007

\section{INTRODUCTION}

Henoch-Schonlein Purpura (HSP) was first described by Schonlein in 1837 and later by Henoch. The disease manifests itself as an autoimmune, self-limiting, multisystem involving, non-granulomatous, small vessel vasculitis. HSP is the most common cutaneous vasculitis among children with nearly $90 \%$ of all reported cases being HSP [1]. The peak incidence occurs in the age group of 4-6 years with a slight male preponderance (male:female $=1.2: 1$ ). In adults, the disease is relatively rare with the estimated incidence varying between 3.4 and 14.3 per million population. Its etiology still remains unclear. Proposed associations include infections (bacterial, viral, and parasitic), medications, vaccinations, malignancies, alpha-1-antitrypsin deficiency, and familial Mediterranean fever [2].

The pathogenesis of HSP still remains unclear. It is postulated that in HSP, immune complexes consisting of predominantly polymeric IgA1 deposit in the dermal, gastrointestinal (GI), and renal capillary bed leading to activation of the alternate complement pathway which leads to neutrophil accumulation resulting in inflammation in the vessel wall without a granulomatous reaction [3].

\section{CASE REPORT}

A 35-year-old female presented with rashes over her legs for the past 1 week. The rash was painful but was not pruritic and predominantly seen over the anterior aspect of the lower two-thirds of both legs. There were no aggravating or relieving factors. She had associated abdominal pain which was intermittent, diffuse, and colicky in nature. She also gave a history of mild hematemesis and melena for the past 2 weeks. She was a known case of rheumatic heart disease - post-mitral valve replacement status on oral anticoagulants (acenocoumarol $2 \mathrm{mg}$ ). On examination, she was found to have a palpable purpuric rash on the lower limbs (Figs. 1 and 2) and also on the upper limbs. Her vitals and systemic examination were normal.

Her laboratory workup revealed normal red blood cell (RBC), white blood cell, and platelet counts. Her baseline renal and hepatic parameters were within limits. She had $3+$ proteinuria by dipstick with 1-2 RBC's on urine microscopy. Her coagulation studies were normal. Her echo and blood culture revealed no evidence of infective endocarditis. Her upper GI endoscopy revealed erosive duodenitis.

Based on the clinical history, workup for vasculitis was done. Skin biopsy revealed leukocytoclastic vasculitis. In view of her use of oral anticoagulant, the possibility of drug-induced leukocytoclastic vasculitis was considered. Cardiologist advised to continue oral anticoagulation as the patient had a metallic valve. Other causes for vasculitis were evaluated. Viral markers (HIV, hepatitis B surface antigen, and antihepatitis $C$ virus) were found to be negative. Antinuclear antibody (ANA) and anti-neutrophil cytoplasmic antibody were also negative. Complement levels (C3 and C4) were normal.

She was started on steroids (intravenous [IV] dexamethasone $8 \mathrm{mg}$ followed by oral prednisolone at a dose of $20 \mathrm{mg}$ OD) which were later tapered over 2 weeks. The patient showed clinical improvement within 48 hrs of initiation of steroids and the rash improved in spite of continued use of acenocoumarol. Proteinuria reduced gradually, and hence renal biopsy was deferred in view of clinical response. The final diagnosis of HSP was made as patient satisfied the clinical criteria for HSP and the rash improved in spite of continuation of oral anticoagulants. Patient remained asymptomatic at 3-month follow-up.

\section{DISCUSSION}

The diagnosis of HSP is based on the classic tetrad of clinical manifestations of the disease. HSP is characterized by nonthrombocytopenic palpable purpura, arthritis or arthralgias, GI and renal involvement, and rarely other systems involvement (lungs, nervous system, and genitourinary tract) [4].

The 2006 European League against Rheumatism and Pediatric Rheumatology European Society criteria for HSP has one mandatory criterion of palpable purpura with lower limb predominance with any one of the following criteria, namely, diffuse abdominal pain, IgA deposition in any biopsy, arthritis/arthralgia, or renal involvement (hematuria and/or proteinuria) was satisfied by our patient [4].

Cutaneous involvement is the most common presentation of HSP with a palpable purpura being seen in $96 \%$ of the cases as the presenting feature. Arthritis was seen in $61 \%$ of patients with HSP. In patients with renal involvement, more than $90 \%$ of patients had proteinuria and hematuria [5]

The differential diagnosis of HSP includes conditions such as Crohn's disease, Wegener's granulomatosis, infective endocarditis, IgA nephropathy, and hemolytic uremic syndrome. Warfarin and other coumarin derivatives have been associated with leukocytoclastic vasculitis and allergic interstitial nephritis. This condition fails to 


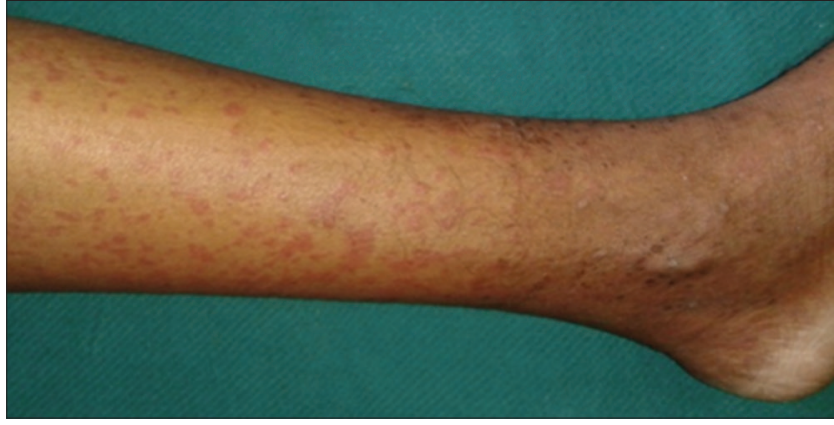

Fig. 1: Purpuric rash over the lateral aspect of leg

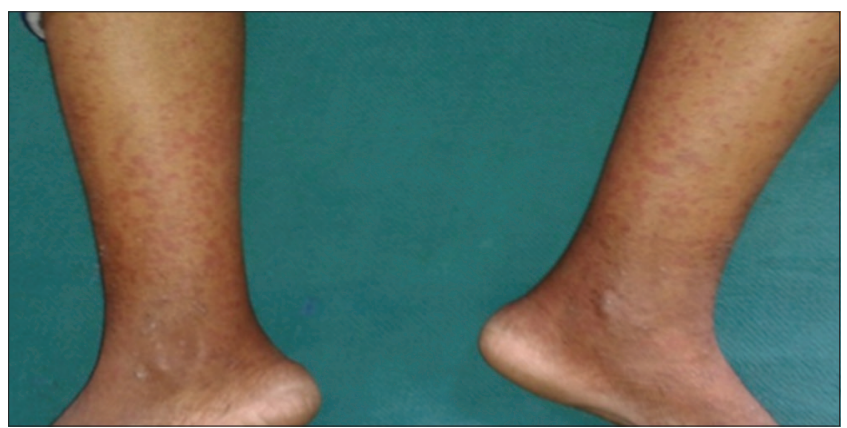

Fig. 2: Purpuric rash over both the legs

respond to initiation of steroids and only responds to cessation of the offending drug [6].

HSP in children is very common and has been extensively studied. It is generally considered a self-limiting disorder. In a large single-center, retrospective study performed in Northern Spain, 417 patients (adults and children) with HSP, complete recovery was observed in most of the patients with a relapse rate of only 31\% [7]. In adults, HSP has been observed to have a higher frequency of systemic involvement. The outcome in adults was found to be similar to children with complete recovery from the disease in the majority of the patients [8].

Acetaminophen and non-steroidal anti-inflammatory drugs can be used in milder forms of the disease. Oral steroids (prednisolone or methyl prednisolone at $1-2 \mathrm{mg} / \mathrm{kg} /$ day) are indicated in patients with severe rash, severe colicky abdominal pain, renal, scrotal, and testicular involvement [9]. Immunosuppressive drugs (cyclophosphamide, azathioprine, cyclosporine $\mathrm{A}$, and mycophenolate mofetil) in combination with high-dose IV pulse steroids are recommended if there is no benefit from steroids alone. Plasmapheresis or high-dose IV immunoglobulin therapy may be recommended for worsening renal function and hemorrhage in the lungs and brain refractory to steroids and immunosuppressive drugs [10].

There are some case reports showing that dapsone or colchicine may be useful in chronic HSP. Since factor XIII levels were found to be low in HSP patients and this correlated with the severity of GI symptoms, factor XIII replacement has also been advocated as an adjunctive therapy in patients with HSP.

\section{CONCLUSIONS}

Although HSP is uncommon in the adults, palpable purpura with multiorgan involvement (GI, kidney, and joints) should lead one to consider small vessel vasculitis in such patients. Prompt diagnosis and early multidisciplinary approach can lead to appropriate management and prevent the potential complications as demonstrated in our case.

\section{REFERENCES}

1. Lane SE, Watts R, Scott DG. Epidemiology of systemic vasculitis. Curr Rheumatol Rep 2005;7(4):270-5.

2. Chen KR, Carlson JA. Clinical approach to cutaneous vasculitis. Am J Clin Dermatol 2008;9(2):71-92.

3. Vogler C, Eliason SC, Wood EG. Glomerular membranopathy in children with IgA nephropathy and Henoch Schönlein purpura. Pediatr Dev Pathol 1999;2(3):227-35.

4. Ozen S, Ruperto N, Dillon MJ, Bagga A, Barron K, Davin JC, et al. EULAR/PReS endorsed consensus criteria for the classification of childhood vasculitides. Ann Rheum Dis 2006;65(7):936-41.

5. Pillebout E, Thervet E, Hill G, Alberti C, Vanhille P, Nochy D. HenochSchönlein purpura in adults: Outcome and prognostic factors. J Am Soc Nephrol 2002;13(5):1271-8.

6. Kapoor KG, Bekaii-Saab T. Warfarin-induced allergic interstitial nephritis and leucocytoclastic vasculitis. Intern Med J 2008;38(4):281-3.

7. Calvo-Río V, Loricera J, Mata C, Martín L, Ortiz-Sanjuán F, Alvarez L, et al. Henoch-Schönlein purpura in Northern Spain: Clinical spectrum of the disease in 417 patients from a single center. Medicine (Baltimore) 2014;93(2):106-13.

8. Blanco R, Martínez-Taboada VM, Rodríguez-Valverde V, GarcíaFuentes M, González-Gay MA. Henoch-Schönlein purpura in adulthood and childhood: Two different expressions of the same syndrome. Arthritis Rheum 1997;40(5):859-64.

9. Ronkainen J, Koskimies O, Ala-Houhala M, Antikainen M, Merenmies J, Rajantie J, et al. Early prednisone therapy in HenochSchönlein purpura: A randomized, double-blind, placebo-controlled trial. J Pediatr 2006;149(2):241-7.

10. Zaffanello M, Fanos V. Treatment-based literature of HenochSchönlein purpura nephritis in childhood. Pediatr Nephrol 2009;24(10):1901-11 